\title{
Frightening Near-Death Experiences Revisited: A Commentary on Responses to My Paper by Christopher Bache and Nancy Evans Bush
}

\author{
Kenneth Ring, Ph.D. \\ University of Connecticut
}

ABSTRACT: In this commentary, I discuss the responses to my paper on frightening near-death experiences (NDEs) written by Christopher Bache and Nancy Evans Bush, and I try to show that there are many points of agreement among us all. While Bache and I saw the ontological status of frightening NDEs differently than did Bush, all of us agreed on the psychological reality and importance of these experiences. Research on frightening NDEs, long overdue, is encouraged and reasons for its urgency are briefly mentioned.

Despite the apparent-and sometimes real-differences in perspectives on frightening near-death experiences (NDEs) between Christopher Bache and Nancy Evans Bush, respectively, and me, I welcome and appreciate their creative and indeed eloquent papers (Bache, 1994; Bush, 1994) on this subject in response to mine (Ring, 1994). Indeed, my hope that my own ideas about frightening NDEs would spark further thinking about these troubling and sometimes traumatic encounters has already been realized by the efforts of these authors, and I feel certain we have only seen the beginning of a new wave of interest in this variety of NDE. In time, we can also expect further research on frightening NDEs, too, which is clearly needed if we are to have the

Kenneth Ring, Ph.D., is Professor Emeritus of Psychology at the University of Connecticut. Reprint requests should be addressed to Dr. Ring at the Department of Psychology, University of Connecticut, Storrs, CT 06269-1020. 
empirical data required to settle definitively some of the outstanding questions on which, for the moment at least, these writers and I can only offer divergent opinions.

In fact, many of the differences between us turn out, on closer analysis, not to be differences at all or to be based on misunderstandings, easily resolved, of some of my remarks. The result is that, as a whole, there is a considerable amount of unsuspected common ground among all three of us, as I will attempt to show. Some differences, and differing emphases, remain of course, and I will not attempt to gloss over these; but let me start my commentary by pointing to the commonalities, beginning with Bache's paper on the perinatal approach to frightening NDEs.

\section{The Perinatal Analysis of Frightening NDEs}

In my view, Bache has done a masterful job in showing how Stanislav Grof's perinatal model can in principle elegantly and parsimoniously subsume many of the phenomenological features of frightening NDEs. In this respect, I accept and admire Bache's formulation as an improved and conceptually more appealing revision of some of the ideas I had presented in my own paper. As a result of his work, we can now discern a clear progression in our attempts to integrate the findings on frightening NDEs, starting from the pioneering article by Bruce Greyson and Bush (1992). Those authors, of course, began by distinguishing three distinct types of frightening NDEs. In my paper, I suggested that we consider inverted and hellish NDEs as variants of one another, but regarded the meaningless void type of experience as something of a different category altogether. Bache, by directing our attention to Grof's model, has found a way to conceptualize them all as variants of a single domain of experience, that stemming from perinatal matrices.

The case for the applicability of Grof's model to NDEs was not original with Bache, of course (Grof himself, together with Joan Halifax, made a compelling argument along these lines as long ago as 1977 in The Human Encounter With Death), but Bache deserves the credit for showing how it can be used to achieve an integrated understanding of the varieties of frightening NDEs in particular. This approach, as he made clear, was not only consistent with the general interpretive line I had suggested, following $A$ Course in Miracles (1975), but took us deeper into the psychodynamics of frightening NDEs than I was prepared to go. With Bache as our Grofian guide, it 
was easy to see that I had certainly failed to make the point that meaningless void NDEs may well shade into hellish experiences as they progress and that, therefore, it may not be justified to distinguish them in quite the way I had suggested.

Nevertheless, I still think there is something to be said on behalf of the interpretation I gave to experiences of the meaningless void type, at least in terms of their precipitating conditions. That brings us directly to the thorny issue of the nature of so-called "emergence reactions," which is of course a medical term, and to the question of whether, in the interests of parsimony, one really needs to invoke them in the first place. In fact, I suspect that Bache and I understand these reactions in a similar way. For my part, I certainly accept the idea that emergence reactions may very well reflect some kind of ego-resistance to surrendering to "ultimate reality" (if I may put it that way), and that the anesthetic simply triggers that response but does not "cause" it.

But I still think it is an empirical question whether such experiences are disproportionately associated with the use of anesthetics as I suggested (and as Bache allowed) and specifically for women in childbirth. Bache may have been right that women giving birth may well be more likely to tune in to the perinatal zone of consciousness, but there would still be a way to provide a test of our separate hypotheses. If I was correct, meaningless void experiences ought to be more commonly found in conjunction with the use of anesthetics generally and especially in childbirth; if Bache was right, they ought to be equally likely for women having natural childbirth as well as those who undergo labor with the help of anesthetics. Theoretically, however, our interpretations of the psychological basis for emergence reactions were virtually identical, it seems to me.

Thus, while emergence reactions in themselves may not be a separate type of frightening NDE, anesthetics may play a distinctive role in abetting NDEs of the meaningless void variety. Only research into the matter can answer this question, but, at least in principle, it should be easy to gather the necessary data.

An especially valuable feature of Bache's paper for me was his pointing to an apparent and hitherto overlooked (at least by me) conundrum pertaining to frightening NDEs. Specifically, if my analysis based on ego-attachment was correct, one would expect to find many more persons reporting frightening NDEs than we do. (Indeed, Bache's perinatal approach implied the same thing.) And he rightly raised the obvious question here: why aren't there more? I am inclined to agree with one of his implied suggestions, namely, there may be something about the NDE that makes it even more powerful than lysergic acid 
diethylamide (LSD) in that it seems to accelerate persons through the kind of psychodynamic and perinatal realms that psychedelic therapy plunges them into.

A crude metaphor here would be that LSD is like a freight train chugging through the unconscious whereas the NDE is a rocket ship that tends to streak through these zones at an incredible speed (as NDErs, in fact, often suggest when they characterize their movement toward the light as involving "the speed of light" or even a supraluminal velocity). This, however, is obviously only a metaphor and not a testable proposition, yet it at least has a certain plausibility, especially when one considers that an LSD trip typically lasts many hours, whereas an NDE may take place in a few minutes or less. At any rate, Bache has again put his finger on a problem that both researchers and theoreticians on frightening NDEs will need to address more searchingly.

Finally, there is one point of convergence between us that not only needs to be mentioned but deserves to be stressed: the ontological status of frightening NDEs. Bache was very clear on this point, and more than once remarked that frightening NDEs, for all their psychological compellingness, do not have the same ontological significance as the classic radiant NDE whose center is the light. From this latter perspective, frightening NDEs are, in effect, merely the shadows of the ego and ultimately just as insubstantial as the ego itself. Frightening NDEs are, in short, phantoms, even though they may scare and torment us more than any earthly terror could ever do.

It is just this explosive mix of devastating impact and undeniable psychological reality that informed Bush's critique of my paper and made her argue against Bache and me that frightening NDEs are comparable ontologically to those of the transcendental variety. In her desire to give ontological parity to frightening NDEs, however, she seriously distorted the implications of my reading of these experiences and failed to see that in practice, if not in theory, we hold very similar views about the significance of frightening NDEs. To find this common ground, we need to see first how she has misconstrued both my intent and my meaning.

\section{Beating Around the Bush}

In effect, Bush's unhappiness with my analysis of frightening NDEs, and especially those of an existential void variety, rested on four charges she laid against me. Let's consider them at the outset. 
First, she claimed that I was playing a reductionist game in apparently asserting that such experiences, at least those of the meaningless void type, could be fully explained as nothing but emergence reactions to anesthesia. Second, she protested that I was stripping frightening NDEs of their rightful and equal ontological status, turning them thereby into some kind of ersatz NDE.

Third, by consigning frightening NDEs to the ontological hinterlands, I seemed to be denying their psychological reality. And finally, by denying their psychological reality, I seemed also to be dismissing them altogether and suggesting that they are mere hallucinations that have nothing to teach the individual who undergoes them or the researcher who would study them.

All of these charges, except the second, are baseless and stemmed, as I have already indicated, from a fundamental misinterpretation on Bush's part of the thrust and implications of my argument. Therefore in this response, I need to address myself to the above four points in order to show that her own fears about my conception of frightening NDEs were largely unwarranted and that, on the contrary, we share a similar sense of the importance of these experiences and the lessons we may all be enabled to learn from studying them.

To begin with, then, was I guilty of suddenly turning into the Susan Blackmore (1993) of frightening NDEs by suggesting that there are psychological and even physiological precursors to these experiences? I hardly think so. Everyone recognizes, for example, that most ordinary dreams are heralded by a distinct set of physiological conditions associated with the onset of rapid eye movement (REM) sleep, yet few of us would argue that the dreams themselves are explained away by these factors. In like fashion, by my offering as testable hypotheses that certain psychological states, such as fear of ego loss or psychological stress reactions to anesthesia, might afford circumstances that conduce to frightening NDEs, I was only pointing to possible triggers for these experiences, not to complete explanations for them.

After all, as I have indicated both in my original article and again in this commentary, one of my interests is to try to promote research into frightening NDEs by drawing attention to certain testable propositions that could confirm or undermine my conception of these NDEs. And even if the empirical evidence here should provide some support for my formulation in this connection, that would not in any way invalidate these experiences but only help us to understand the conditions that tend to give rise to them in the first place.

As to the ontological issue, this is the one point where there is a true divide between Bush, on the one hand, and Bache and me on the other. 
Empirics will not help us here; this has more to do with personal axiomatic presuppositions relevant to the NDE itself. All I can do here is to restate my thesis as clearly as I can, try to make a case for it, and let the reader decide for himself or herself.

In the world of ordinary duality, seen through the eyes of the ego, of course there is good and evil, heaven and hell, and so forth. That's true by definition. And we take our ego with us into the first stages of the NDE where we retain our sense of separateness. No matter that the ego is ultimately an illusion that gives rise to this false sense of separateness; it is the lens through which we have become accustomed to see the world and we don't know any other way. The ego is also a defensive system and is very much concerned with perpetuating its own survival. It desperately doesn't want to die, and when it feels threatened-unless it is absolutely and suddenly overwhelmed-it will throw up whatever roadblocks it can to resist its demise.

It is the Light that is its ultimate enemy, because on entering it the ego begins to become transparent to itself. Its game is up when the true Light of our Being - which is All Being and Everything, our primordial and eternal essence-begins to shine. The last refuge of the ego before it surrenders is formed by the wall of fear it mounts to keep out the Light. As Bob Helm, a Canadian NDEr whose full experience I previously recounted in this Journal (Ring, 1991), recently remarked to me (B. Helm, personal communication, April 9, 1993):

If we could but let go of our fears, we could indeed experience the Light right now! . . . To get back to where we are meant to be spiritually, we must be willing to look deeply into ourselves, find the fear and let it go, and in inner discovery let go our attachments to the darkness of Earth. For if we experience thoughts of fear, no matter how little, we to some degree block the Light, and it is of this Light that we ourselves are created.

Jayne Smith, another NDEr, once remarked that we are on a journey back to God (Smith, 1987), and many NDErs have commented that when they enter the Light, they realize that they are finally home, that they recognize it, that in a sense they have always been there but had just forgotten it. Joe Geraci, for example, once reflected that when he entered the Light he found that "It was eternity. It's like I was always there and I will always be there, and that my existence on earth was just a brief instant" (Ring, 1984, p. 54). And Beverly Brodsky, another NDEr whose account appeared in the same article as Bob Helm's, concluded her narrative by emphasizing its absolute reality and its undeniable qualities: 
Nothing that intense and life-changing could possibly have been a dream or hallucination. To the contrary, I consider the rest of my life to be a passing fantasy, a brief dream, that will end when I again awaken in the permanent presence of that giver of life and bliss.

For those who grieve or fear, I assure you of this: there is no death, nor does love ever end. And remember also that we are aspects of the one perfect whole, and as such are part of God, and of each other. Someday you who are reading this and I will be together in light, love, and unending bliss. (Ring, 1991, p. 17)

These are the kind of testimonies-and they are abundant in the literature of NDEs, of course - that have led me to posit the Light as a manifestation of ultimate reality, next to which the terrified cries of the ego and its frightening images have no more substance than scenes from a horror film into whose absorbing illusions we have fallen. The NDE wakes us up from this nightmarish existence by revealing to us that our true nature is what in yoga is called Sat-Chit-Ananda: existence, knowledge, bliss. As Shankara, the great exponent of Vedanta, observed more than a millenium ago (as paraphrased in the introduction to his most famous work, Crest-Jewel of Discrimination):

When the illumined soul passes into transcendental consciousness, he realizes the Self as pure bliss and pure intelligence, the "One without a second." In this state of consciousness, all perception of multiplicity ceases, there is no longer any sense of "mine" and "thine," the world as we ordinarily know it has vanished. Then the Self shines forth as the One. (Prabhavananda and Isherwood, 1970, p. 14)

The "One without a second" is precisely what the NDEr is enabled to experience when penetrating into the heart of all creation-the Light. When NDErs such as Diane Morrisey say things like "this was a love that didn't know hate" (Barnett, 1983), or when Patrick Gallagher avers, in speaking of the realm of Light, "I knew immediately that there was no night there" (Barnett, 1983), they are echoing the same insight. They have found themselves on a nondual ontological bedrock that is as self-evident to them as reading this print is to you.

Yes, the journey back to God may take us through the torments of hell-no one denies that-but when we arrive at our goal, if these NDErs are right, we see truly for the first time in the way Shankara (and many others) have described for us, and what seemed so real at the time dissolves into the illusion it was all along, as does our sense of separate identity.

But of course in ordinary daily life, as Bush made clear, we live in our ego-based world, which seems anything but an illusion. And it is just here, in the all-too-familiar round of our quotidian existence, that I 
find myself virtually at one again with Bush's valuation of the frightening NDE and its seminal importance.

To be brief, denying frightening NDEs ultimate ontological status does not in any way call into question their psychological reality, nor does it imply I am according these NDEs some kind of secondary status in the pantheon of experiences we in this field of near-death studies choose to devote ourselves to. Bush was simply wrong to suggest that I would tell such an experiencer that "nothing happened." After my own metaphysically terrifying ketamine experience (Ring, 1994), no one could have convinced me that "nothing happened"! Of course, these experiences are important, and they must never, ever, be cavalierly dismissed as some kind of mere psychological anomaly of no consequence.

Similarly, we already know or can surmise that they have a deep impact on the lives of persons who undergo them. Consider, as an exemplification of this, the case of Howard Storm, described in my original paper (1994). Here is a man who by his own admission underwent his own hero's journey, encountering demonic entities of the most terrifying sort who came close to annihilating him, and who passed through these ordeals and emerged totally transformed by his experience so that he could be truly said to have been born anew.

Such transformations-and the lessons we all can learn from studying such cases-stemming from frightening NDEs are just as significant as those that derive from beatific encounters with the light and equally deserve our respectful attention. Indeed, precisely because they have been ignored in the field of near-death studies, research on them is long overdue. As Bush would, I'm sure, be the first to concede, however, we really have no careful work at all on how these experiences affect the individuals who undergo them, or even whether the familiar pattern of aftereffects for NDEs holds for them.

Certainly there is no question-and here I am completely in accord with Bush - that confronting the darker side of our natures and experience is absolutely essential in the process of psychospiritual growth, and that frightening NDErs are as of now a largely untapped resource whose neglect we can no longer condone. After all, as Bache has helpfully reminded us, if even the great souls of our own Western spiritual tradition have had to do battle with their demons in their journeys toward wholeness, who could ever argue that these fierce battles are not an indispensable requirement for anyone who would seek the Light? Even NDErs who come to bask in it may have to endure the agony of the life review and experience for themselves the pain they have deliberately or inadvertently inflicted on another. Life's trials, both here and hereafter, have much to teach us, and frightening NDEs beckon to all who would learn from them. 


\section{Conclusion}

I hope I have been able to show in this commentary that the differences among Bache, Bush, and me are not nearly so divisive as their papers may have suggested and that, in truth, we do indeed share much common ground in our views and in the importance we place on frightening NDEs. In this connection, I need to say again that I find Bache's theoretical formulation, based on Grof's perinatal model, to be an improvement over mine, and that I was already fully in agreement with Bush's stance with respect to the need to study such experiences and their aftermath more carefully.

It should be obvious, I trust, that my original paper (1994) was an effort to encourage precisely such research, both by pointing to certain empirical questions that could be investigated, and by trying to show the relevance of a variety of larger perspectives, such as Grof's and that stemming from $A$ Course in Miracles (1975), in terms of which to understand the nature and significance of frightening NDEs. In this respect, the amplifications provided by Bache and Bush in their papers were extremely helpful and together I hope the ideas of all of us who have been involved in this exchange of views will be fruitful to other researchers and scholars who will come to explore this type of NDE.

And to bring one other and perhaps more exigent note to this discussion, I would like to conclude by saying that not only is such research long overdue, but now more than ever it may be necessary for those of us with a stake in the integrity of the field of near-death studies to conduct it. Along with some of my colleagues, I have been disturbed of late by a seemingly growing tendency of the religious right to appropriate the findings of near-death research-especially regarding frightening NDEs - to serve its own dogmatic ends. This it certainly has a right to do, along with everyone else, but the uses to which our paltry database of such cases has been put by persons of fundamentalist leanings seem to be both exploitive and misleading. Perhaps this is still another reason, then, for researchers and scholars in the field to provide solid information about frightening NDEs shorn of the fervor of special pleading and religious proselytizing.

\section{References}

Bache, C.M. (1994). A perinatal interpretation of frightening near-death experiences: A dialogue with Kenneth Ring. Journal of Near-Death Studies, this issue.

Barnett, W. (1983). Dying, death, and beyond [Videotape]. San Jose, CA: Gill Cable.

Blackmore, S. (1993). Dying to live: Near-death experiences. Buffalo, NY: Prometheus. 
Bush, N.E. (1994). The paradox of Jonah: Response to "Solving the riddle of frightening near-death experiences." Journal of Near-Death Studies, this issue.

Course in miracles, A. (1975). Tiburon, CA: Foundation for Inner Peace.

Greyson, B., and Bush, N.E. (1992). Distressing near-death experiences. Psychiatry, 55, 95-110.

Grof, S., and Halifax, J. (1977). The human encounter with death. New York, NY: Dutton.

Prabhavananda, S., and Isherwood, C. (1970). Shankara's crest-jewel of discrimination. New York, NY: Signet.

Ring, K. (1984). Heading toward omega: In search of the meaning of the near-death experience. New York, NY: Morrow.

Ring, K. (1991). Amazing grace: The near-death experience as a compensatory gift. Journal of Near-Death Studies, 10, 11-39.

Ring, K. (1994). Solving the riddle of frightening near-death experiences: Some testable hypotheses and a perspective based on A course in miracles. Journal of Near-Death Studies, this issue.

Smith, J. (1987). Moment of truth [Videotape]. Springdale, AR: Ozark Video. 